\title{
The phonology and phonetics of prenuclear and nuclear accents in French
}

\author{
Mariapaola D'Imperio ${ }^{1}$, Roxane Bertrand ${ }^{1}$, Albert Di Cristo ${ }^{2}$ and Cristel \\ Portes $^{2}$ \\ ${ }^{1}$ Laboratoire Parole et Langage - UMR 6057 CNRS, Aix-en-Provence, France \\ ${ }^{2}$ Université de Provence and Laboratoire Parole et Langage - UMR 6057 CNRS, \\ Aix-en-Provence, France \\ https://doi.org/10.36505/ExLing-2006/01/0024/000024
}

\begin{abstract}
The goal of this paper was to determine whether there is a formal difference between high-ending nuclear (IP-final) and prenuclear accents in French. After transcribing the relevant items, we then compared the different accentual and phrasal categories by analyzing, among the other things, the tonal and temporal characteristics of their tonal targets as well as durational characteristics of the target syllables. The hy-pothesis tested is that nuclear accents differ from prenuclear ones in terms of formal characteristics of the contour which cannot be explained, for instance, by invoking the presence or absence of an upcoming tone. We show that both alignment and scaling differences can be found between the two accents types, thus motivating a contrastive phonological analysis.
\end{abstract}

\section{Introduction}

Despite the very large body of literature on prosody in French, there is still no consensus about which and how many constituents should be included in the prosodic hierarchy as well as which differences between contours are categorical. Two influential models of French intonation posit the existence of two prosodic constituents, a higher level one which can be identified with the Intonation Phrase (IP), and a lower level which is either defined in purely tonal terms, as in the case of the AP posited by Jun and Fougeron (2002) or as a rhythmic constituent which is build on the basis of prosodic phonological rules thus with reference to the syntax. This is the case of the phonological phrase of Post (2000).

Higher in the prosodic hierarchy (being also the highest level), we find the IP. Traditionally, this last phrasing level is also the domain of the "nuclear accent", which is positionally defined as being the last accent within this constituent, as well as being the most prominent one in the prosodic hierarchy. Any preceding accent in the intonation phrase is defined as "prenuclear".

ExLing 2006: Proceedings of 1st Tutorial and Research Workshop on Experimental Linguistics, 28-30 August 2006, Athens, Greece 
122 M. D'Imperio et al.

Within the autosegmental-metrical model of intonation, only the positional definition remains, though defining a lower phrasing level, that of the intermediate phrase. Specifically, the nuclear accent is the accent immediately preceding the phrase accent. In the models of French intonation proposed by Jun and Fougeron (2002) and Post (2000) there is no formal distinction between nuclear and prenuclear accent type. However, Di Cristo (1999), claims that a phonological distinction between these two accents should be kept for French.

This work aims at investigating the potential difference between an IPfinal rising contour and an IP-internal (for instance, accentual-phrase final) rising contour, which are usually described as containing the same rising pitch accent. Specifically, the pitch accent associated with the "primary stress" position in standard French has been described as either a $\mathrm{H}^{*}$ (Post, 2000) or as a LH* (Jun \& Fougeron, 2002) pitch accent.

\section{Corpus and Methodology}

Our corpus (D'Imperio et al., 2006) consisted of sentences in which the same syllable [mi] could occur either in IP-final or non-final position of leftdislocated sentences (e.g., Les amis de mami, ils ne viennent que demain "The friends of grandma, they will only come tomorrow"), and was always potentially at least AP-final. Moreover, we varied the syllable structure between open and closed as well as the number of APs within the IP (2 or 3).

Four speakers of French participated into the experiment. Here we will present data relative only to two speakers.

As for the acoustic measures, alignment and scaling were considered as indices of tonal structure. We also believed that in order to get the most complete view of the phenomenon at hand we needed to follow a double approach. That is we performed both an auditory and an acoustic analysis of the contours. The auditory transcription was performed by two experts, and aimed at distinguishing between a rising $(\mathrm{R})$ versus a high (or same, S, relative to preceding syllable) level $(\mathrm{S} / \mathrm{H})$ accent at the primary stress location. Moreover, since it was particularly difficult to manually identify the location of $\mathrm{L}$ targets, we employed a semi-automatic procedure described in D'Imperio et al. (in press).

\section{Results and Discussion}

The results for the auditory transcription show complete agreement for IPfinal accents, which were all transcribed as rises, while the agreement was much lower for non-final accents (speaker SC: Kappa $=0.02$; speaker SD: Kappa $=0.1$. Note that, despite the higher disagreement within the non-final 
position, almost $80 \%$ of agreed $\mathrm{H}(\mathrm{S} / \mathrm{H})$ accents were detected for speaker SD, while mostly LH rises (R) were detected for speaker SC. Hence, the accent type transcribed for the two subjects was not the same in prenuclear position. This called for investigating the difference acoustically.

Here we present acoustic results for one speaker (SC), since the behaviour for the other speaker was comparable. Figure 1 (upper, left) shows F0 height for the $\mathrm{H}$ target in both prenuclear (first) and nuclear (last) position.
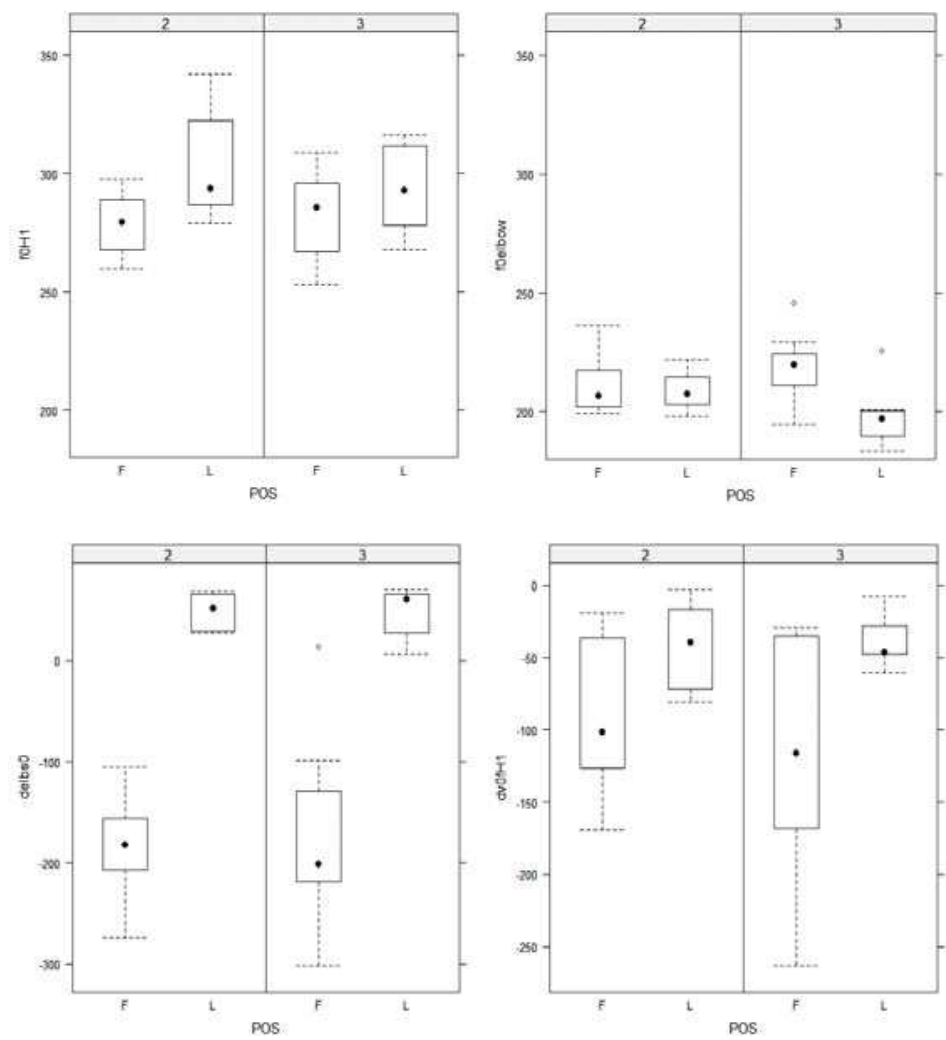

Figure. 1 Mean F0 values of the $\mathrm{H}$ targets (upper, left) and of the $\mathrm{L}$ targets (upper, right) by position within the IP ( $\mathrm{F}=$ first; $\mathrm{L}=$ last) and by number of APs within the IP ( 2 vs. 3 ). The lower section shows $\mathrm{L}$ alignment relative to stressed vowel onset (lower, left) and $\mathrm{H}$ alignment relative to stressed vowel offset (lower, right).

As expected, we found higher F0 values for the nuclear (last) $\mathrm{H}$. Note also a tendency for prenuclear $\mathrm{Hs}$ to be higher in 3-AP items than in 2-AP items. F0 values for the $\mathrm{L}$ target are also shown in Figure 1 (upper, right). 
Unexpectedly, we found greater values in prenuclear position only for 3-AP items. The bottom of Figure 1 shows alignment results of the $\mathrm{L}$ target relative to stressed syllable onset (lower, left), while $\mathrm{H}$ alignment was measured relative to the offset of the stressed vowel (lower, right). Note that L alignment was earlier for prenuclear rises, while $\mathrm{H}$ alignment was later (closer to stressed vowel offset) for nuclear rises, though this measure is less consistent for the prenuclear $\mathrm{H}$.

Our study shows that the hypothesis of the similarity between nuclear and prenuclear accent in French is not supported neither by transcription nor by acoustic data. Nuclear rises are higher, and both its $\mathrm{H}$ and $\mathrm{L}$ targets are later than in prenuclear rises. The alignment differences found cannot be simply accounted for by the presence of a $\mathrm{H} \%$ in nuclear position. The earlier $\mathrm{H}$ alignment in prenuclear position is not due to the presence of a L boundary tone or phrase accent at the end of the AP, since the falling contour following the AP-final rise does not seem to have a fixed slope (Jun and Fougeron, 2002). Moreover, the F0 raising effect on the $\mathrm{L}$ target of prenuclear rises in 3-AP items could be due to a preplanning effect, and should be further investigated.

The old distinction between prenuclear and nuclear accents in traditional intonation studies cannot be completely dismissed for French. Hence, we propose a phonological analysis of this contour as consisting of a prenuclear $\mathrm{H}^{*}$ vs. a nuclear $\mathrm{L}(+) \mathrm{H}^{*}$ gesture. The differences reported need further exploration through additional acoustic data, especially of spontaneous speech (cf., Portes and Bertrand (2005)), as well as through perception experiments, to verify whether the accent type opposition has a categorical nature.

\section{References}

Di Cristo, A. 1999. Le cadre accentual du français contemporain: essai de modélisation. Langues 2(3): 184-205, 2(4): 258-267.

D'Imperio, M., Bertrand, R., Di Cristo, A. and Portes, C. 2006. The phonology and phonetics of prenuclear and nuclear accents in French, LSRL 2006, Rutgers, New Jersey, March 31-April 2, 2006.

D’Imperio, M., Espesser, R., Loevenbruck, H., Menezes, C., Welby, P. et Nguyen, N. (in press). Are tones aligned with articulatory events? Evidence from Italian and French. In Cole, J. and Hualde, J. (eds.) Papers on Laboratory Phonology IX, Oxford : OUP Press.

Jun, S.-A. and Fougeron, C. 2002. Realizations of accentual phrase in French intonation. Probus 14, 147-172.

Portes, C. and Bertrand, R. 2005. Some cues about the interactional value of the "continuation" contour in French. Proceedings of IDP05, oct. 8-9, Aix-enProvence, France.

Post, B. 2000. Tonal and phrasal structures in French intonation, The Hague: Holland Academic graphics. 